\title{
Experimental Investigation of High-Strength Structural Steel Welds
}

\author{
Hajro Ismar1, ${ }^{*}-$ Zijah Burzic $^{2}$ - Nenad J.Kapor ${ }^{3}$ - Tugomir Kokelj4 \\ ${ }^{1}$ University of Sarajevo, Faculty of Mechanical Engineering, Bosnia and Herzegovina \\ 2 Military Technical Institute, Serbia \\ 3 University of Belgrade, Faculty of Mechanical Engineering, Serbia \\ 4 University of Defence, Military Academy, Serbia
}

Material toughness becomes more significant material mechanical property, as well as design variable with recent advances of fracture mechanics understanding. Also, toughness is a particularly important parameter for novel structural materials such as high-strength steels. Furthermore, due to the fact that high-strength steels are mainly used in various welded structures, evaluation of welded joint mismatched properties, including toughness, become particularly important. Therefore, the following paper presents investigation results of impact and quasi-static toughness distribution and mismatch on high-strength steels welds. Welded joint's characteristic heterogeneous zones are obtained by mean of real welding and welding simulation. Finally, relation terms between various mechanical properties, including toughness, for further simplified engineering prediction are provided.

Keywords: toughness, fracture mechanics, high-strength steel, welds, mismatch.

\section{O INTRODUCTION}

Benefits of high-strength steels, HSS, are well known. However, to meet the necessary design and exploitation requirements for various steel structures, a number of factors must be considered wheb selecting HSS. These factors should include at least a reduced deformability, weldability and demanding toughness. Moreover, due to the unfavourable yield stress to tensile strength ratio, $Y / T$, and reduced ductility, those steels are mostly not allowed for use for some demanding steel structures due to the limitations set in design codes [1] to [4]. Development of novel structural integrity assessment procedures based on fracture mechanics, such as the international FITNET procedure [5], a more reliable and confident assessment is possible for various types of structures. Here, the important property of materials, particularly of welded joints, the presence of material flaws, such as cracks, as well as material toughness and components stress state are required to assess particular component for a level of integrity. Moreover, there is a trend in national specifications, and in some international design codes for a particular type of structures, to apply fracture mechanics methods already in a design phase [6] and [7]. Furthermore, there is a trend that conventional qualification of welding procedures may require additional testing of fracture mechanics parameters on test coupons [5] to [7]. Never the less, a general toughness of high-strength structural steel present particular issue. However, toughness should be considered from the point of predicted or design loads. Therefore, according to fracture mechanics principles, at least the following toughness parameters should be considered [5] and [8]:

- Quasi-static toughness, represented by elastoplastic fracture mechanics, EPFM, resistance curves, e.g. $J-\triangle a$ or $C T O D-\triangle a$; where $J$ is $J$-integral in $\left[\mathrm{kJ} / \mathrm{m}^{2}\right], C T O D$ is crack tip opening displacement in [mm] and $\Delta a$ is crack growth in $[\mathrm{mm}]$; and characteristic initiation or materials critical values, e.g. $J_{I c}\left[\mathrm{~kJ} / \mathrm{m}^{2}\right], C T O D_{I c}[\mathrm{~mm}]$; as well as linear-elastic fracture mechanic parameter, $L E F M$, fracture toughness, $K_{I c}\left[\mathrm{MPa} \cdot \mathrm{m}^{0.5}\right]$.

- Impact toughness, represented by resistance curves, $K V-T$ or $D L-T$; where $K V$ is total impact absorbed energy in $[\mathrm{J}], D L$ is percentage of shear fracture in [\%], and $T$ is testing temperature in $\left[{ }^{\circ} \mathrm{C}\right]$; and therefore characteristic transition temperatures (depending on applied criteria), $T_{T}$ in $\left[{ }^{\circ} \mathrm{C}\right]$. In addition, $K V$, may be evaluated for its parts, the so called crack initiation energy, $K V_{i}[\mathrm{~J}]$ and crack propagation energy, $K V_{p}[\mathrm{~J}]$. Determination of $K V_{i}$ and $K V_{p}$ are also based on one kind of resistance curve, e.g. $F$ - $t$, where $F$ is impact force in [N] and $t$ is time in [s] [4].

Furthermore, from the point of fracture mechanics and structural assessment procedures [5] to [10], a higher confidence and less conservatism may be achieved if material resistance properties, as well as applied stress condition are better known. Here, another problem arises: Can sophisticated experimental evaluation of various fracture mechanics parameters, as well as stress state be performed? Therefore, from the point of the fracture mechanics parameters evaluation, novel assessment procedures 
recognize approximation or relationship terms to evaluate rather "complicated" parameters, on basis of "simplified" ones. Even this paper does not deal with evaluation of stress state; various analytical and numerical approaches for evaluation of stress state are known.

It is not an intention of this paper to underestimate other general material toughness parameters, such as those related to dynamic-cyclic loads, e.g. material fatigue resistance, and corresponding fatigue resistance curves and appropriate critical values represented in known $d a / d N-\Delta K$ format, where $d a / d N$ is fatigue crack growth rate, e.g. $d a$ in [mm] and $d N$ in [cycles] are crack growth and number of cycles, respectively, and $\Delta K\left[\mathrm{MPa} \cdot \mathrm{m}^{0.5}\right]$ is stress intensity factor.

Furthermore, because HSS are mainly used for the manufacturing of welded structures, welded joints resistance properties become particularly important. Here, well known microstructural heterogeneity and mismatch of mechanical properties of a complete joint must be carefully considered and evaluated. In addition, because welded joint presents typical structural joints with generated micro and macro faults (considered as cracks), the need for the application of fracture mechanics arises.

Therefore, this paper shows approach and experience on selected toughness properties investigation of HSS welds.

\section{EXPERIMENTAL PROCEDURE}

Similary to the tests in [11] and [12], which have evaluated the hardness of quenched and tempered (QT) steels for particular machine elements, related to cooling time $t_{8 / 5}$ [13], as well as research work of structural steels in [1], this research has also considered and investigated two HSS QT steels: S690QL and S890QL according to EN 10025-6 ( $Q$ for quenched and tempered delivery condition; $L$ for the required impact toughness of $27 \mathrm{~J}$ at $-40{ }^{\circ} \mathrm{C}$ ). On each steel, pairs of test coupons are butt welded, in PA (flat) position, using gas metal arc welding, GMAW, process and $82 \% \mathrm{Ar}+18 \% \mathrm{CO}_{2}$ shielding gas. Generally, described welding conditions are shown in Table 1. Filler materials (FM), delivered in accordance to EN 12534 [14], were G $695 \mathrm{M}$ Mn3Ni1CrMo for S690QL, and G $896 \mathrm{M} \mathrm{Mn4Ni2CrMo} \mathrm{for} \mathrm{S890QL,}$ of $1.2 \mathrm{~mm}$ diameter, are selected on the basis of recommendation of a respective manufacturer. In fact, the FM was of a similar class (chemical composition and weld metal mechanical properties [2] and [14]) as the base materials (represented with carbon equivalent, CET, as shown in Table 1).

Table 1. Welding conditions

\begin{tabular}{|c|c|c|c|c|c|}
\hline steel & thickness & preheat & $Q$ & $t_{8 / 5}$ & $C E T_{B M}$ \\
\hline S690QL & $30 \mathrm{~mm}$ & $200^{\circ} \mathrm{C}$ & 14 to $18 \mathrm{~kJ} / \mathrm{m}$ & 6 to $8 s$ & 0.306 \\
\hline S890QL & $20 \mathrm{~mm}$ & $150^{\circ} \mathrm{C}$ & 1.7 to $1.0 \mathrm{nom}$ & 政 & 0.350 \\
\hline
\end{tabular}

In Addition to specimens with an initial crack in the base, BM, and weld metal, WM, for evaluation of quasi-static toughness, an additional set of specimens for the evaluation of impact toughness is prepared with an initial notch in the base and weld metal, as well as in a heat affected zone, HAZ. The selection of welding parameters was made on the basis of good engineering experiences and a general recommendation given in EN 1011-2 [1] , [4] and [13], as well as on the basis of steel manufacturer recommendation, based on the optimum cooling time concept, e.g. $t_{8 / 5}$, in range of 5 to $15 \mathrm{~s}$. Typical specimen sampling plan is shown in Fig. 1.

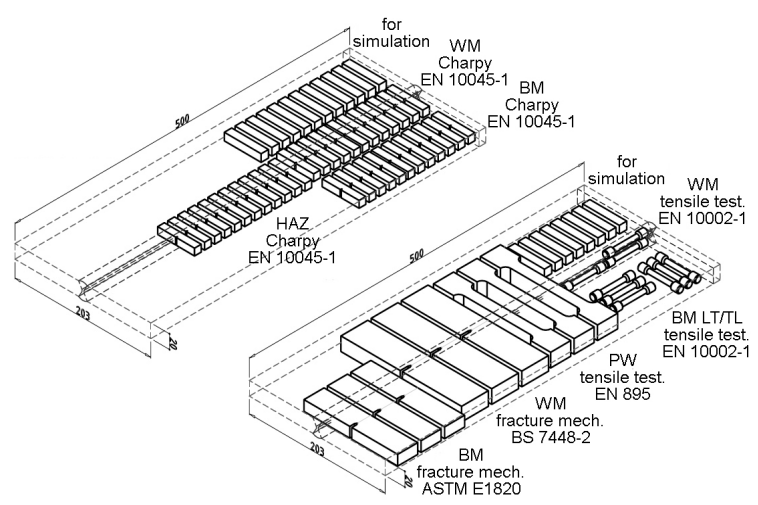

Fig. 1. Example of specimen sampling plan for the pairs of welded test coupons on steel S890QL

Due to the fact that a well known weakest weld zone within coarse-grain heat affected zone, CGHAZ, cannot be evaluated from real welds; additional specimens for welding simulation, and further impact toughness testing were prepared. Welding simulation was performed on thermo-mechanical simulator SmithWeld, in a condition similar than for real welding, e.g. for CG-HAZ with $T_{\max }=1300{ }^{\circ} \mathrm{C}$, and $t_{8 / 5}$ in range of 6 to $7 \mathrm{~s}$ (as shown for real welding on Table 1). In fact, the welding simulation correspond to the determined input thermo-cycle $\left(T_{\max }, t_{8 / 5}\right)$ [4]. Fig. 2 shows the applied thermo cycle for the welding simulation, as well as representative specimen during simulation.

Necessary initial testing consisting of chemical composition testing, hardness distribution testing and 
tensile testing were also performed. In addition, even if is not a subject of this paper, the microstructural evaluation of complete weld joints was performed. Briefly, base metal consists of tempered martensitic microstructure; weld metal consists of dendrite low carbon martensitic microstructure, while HAZ consist of a mixture of martensitic-ferite-bainite microstructure. Appropriate weld joint hardness distribution is shown in Fig. 3. Therefore hardness mismatch, MM, or exactly the undermatching, UM, between weld and base metal, WM/BM, was in the range of $M M_{H V}=U M_{H V}=0.97$ to 0.99 . for both steel's welded joints.

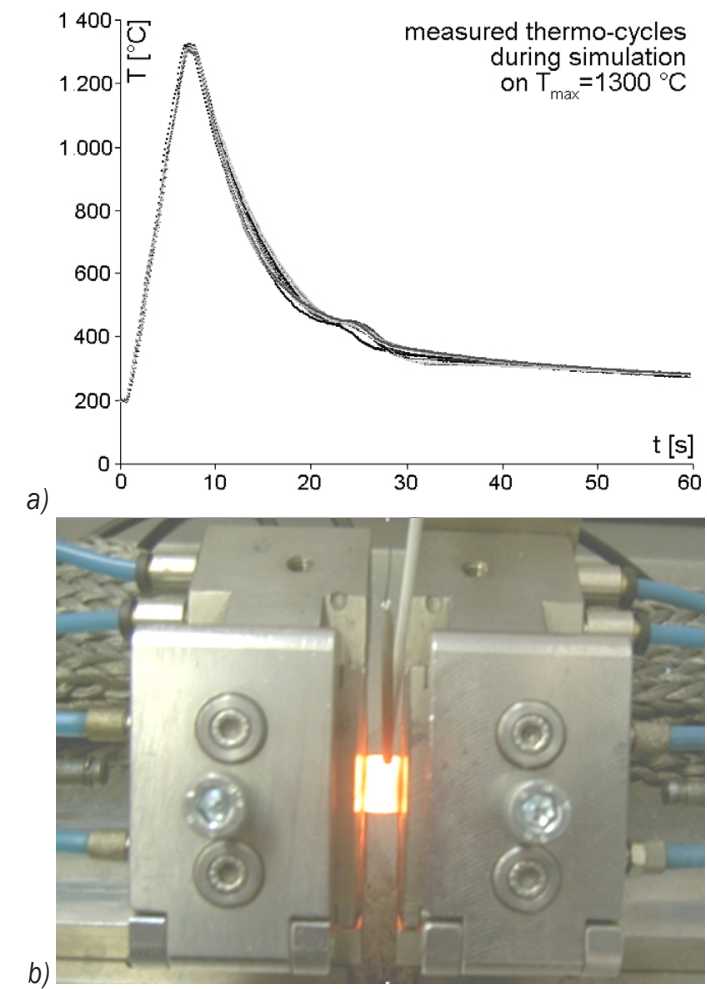

Fig. 2. a) Applied (measured) thermo cycles and b) typical specimen during welding simulation

In addition, results of tensile testing Fig. 4. show the following mismatch of strength and ductility, between weld and base metal, for both steel's weld joints:

- for yield stress, $M M_{R p_{02}}=0.89$ to 0.96 ,

- for tensile strength, $M M_{R_{m}}=0.93$ to 0.95 ,

- for cross-section contraction, $\mathrm{MMz}=0.85$ to 0.92 .

Moreover, the general range of yield stress to tensile strength ratio, for both steel, for BM and WM, was found to be in the range of $Y / T=0.89$ to 0.96 .
Welded joints macro sections as well as corresponding hardness distribution, tested in accordance to EN 1043-1 [15] are shown in Fig. 3.

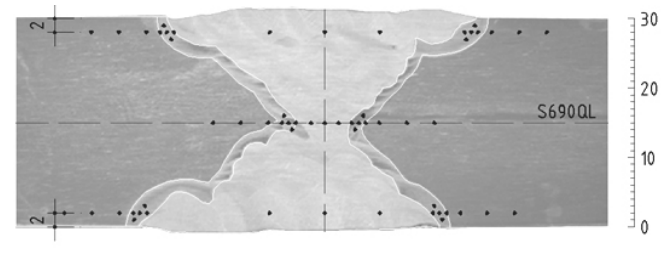

a)
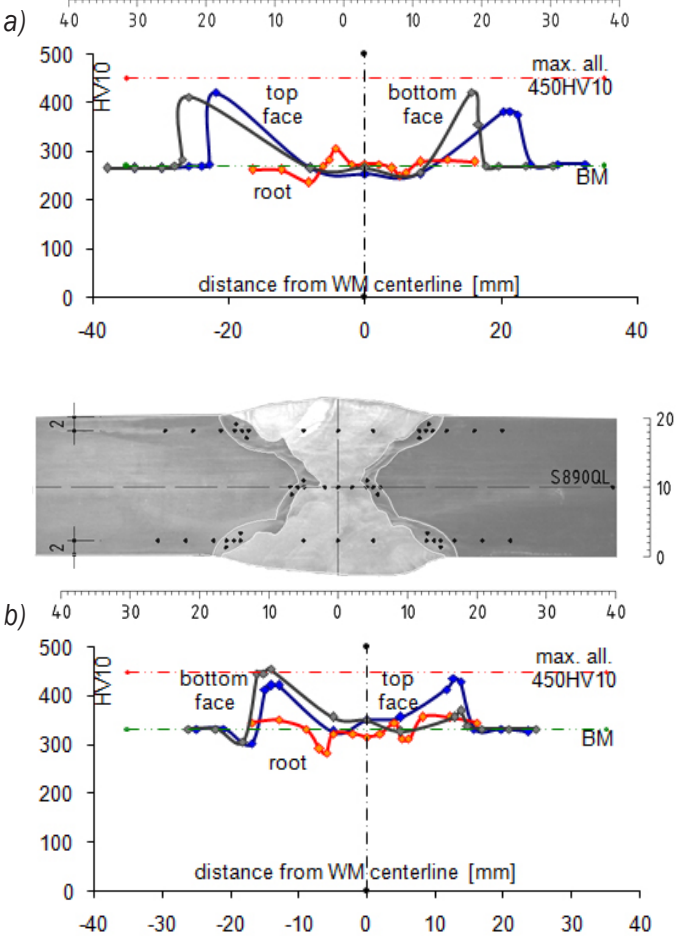

Fig. 3. Welded joints macro section and hardness distribution; a) welded joint on S690QL, b) welded joint on S890QL

The resistance stress-strain curves, $R$ - $A$ Fig. 4, designated as PW present the results for specimen sampled perpendicular to the line of the welded joint. Testing of such specimen is common for the welding procedure qualification.

\section{RESULTS OF TOUGHNESS TESTING}

Typical resistance curves, $F$ - $t$, of impact toughness testing using instrumented Charpy pendulum are shown in Fig. 5. The corresponding results of impact toughness testing on various testing temperatures are shown in Fig. 6.

The impact toughness testing were done in acc. to EN 10045-1 [16], while EPFM parameter testing was done in acc. to ASTM E1820 [9] and BS 7448-2 [10]. Each impact toughness specimen testing has provided 
a)

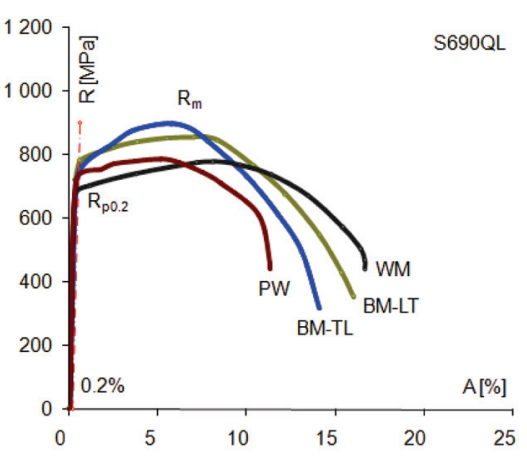

b)

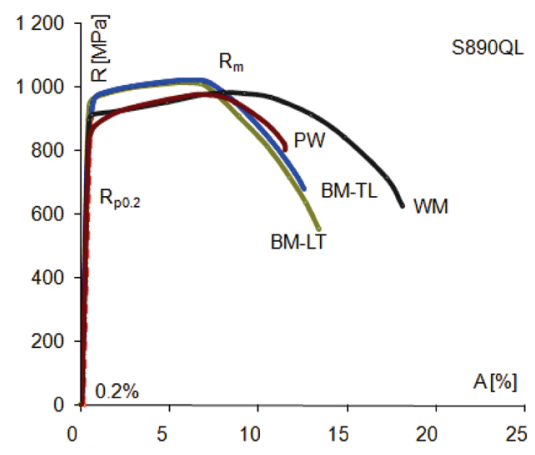

Fig. 4. Typical results of tensile testing (resistance curves) of real welded joint specimens; a) welded joint on S690QL, b) welded joint on S890QL

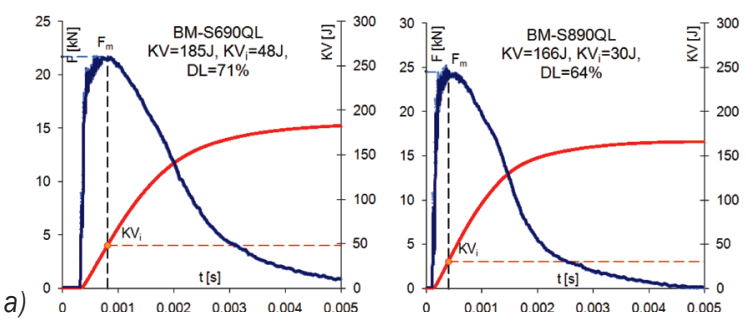

b)
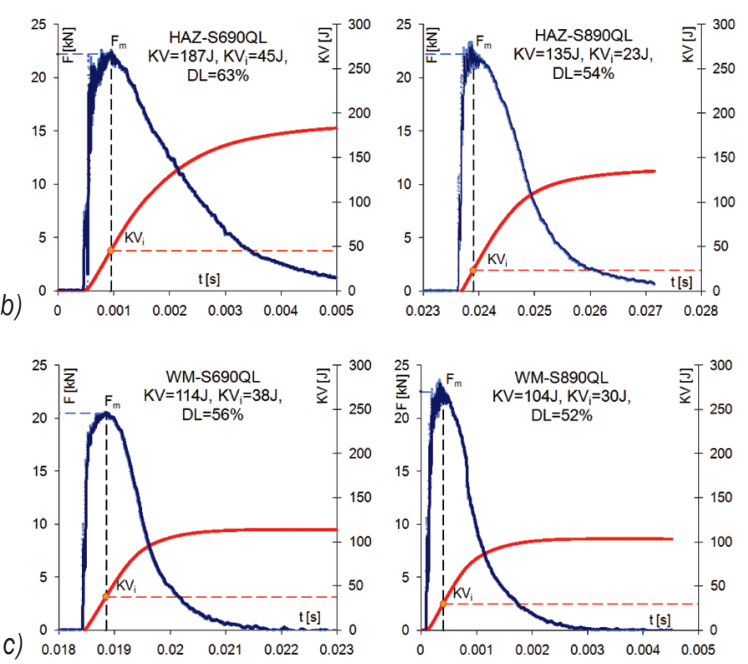

Fig. 5. Typical results of impact toughness at room temperature with initial notch in a) BM, b) $H A Z$ and c) WM
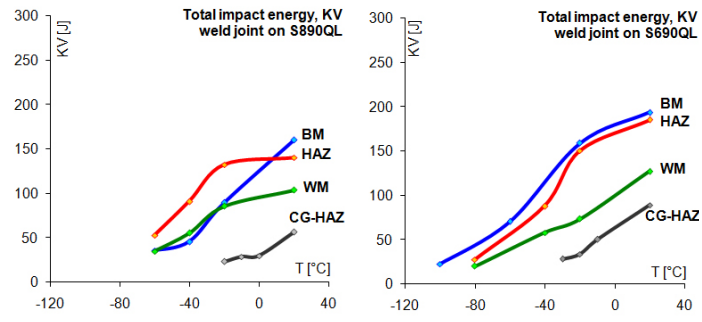

b)

Fig. 6. Total impact energy vs. testing temperature for specimens with initial notch in BM,HAZ and WM; a) welded joint on S690QL, b) welded joint on S890QL
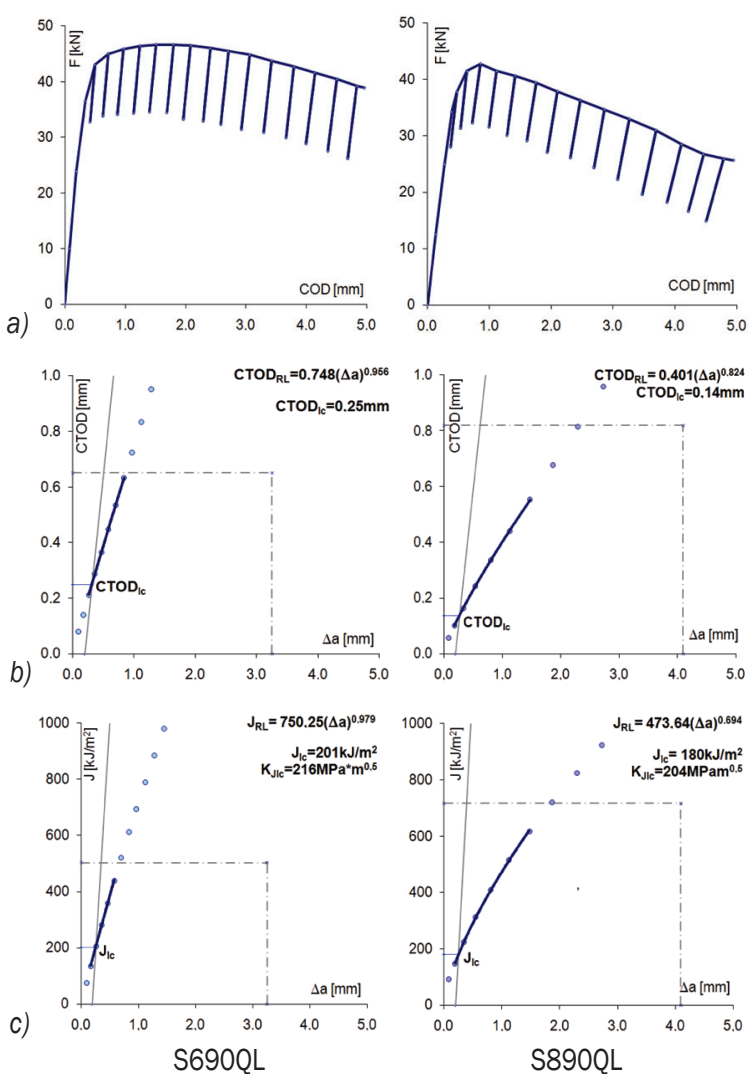

Fig. 7. Typical EPFM resistance curves for BM: a) F-COD, b) CTOD- $\Delta a$, c) $J-\Delta a$

appropriate results for $K V, K V_{i}, K V_{p}$ and $D L$. The impact toughness dependence on testing temperature, from -100 to $+20{ }^{\circ} \mathrm{C}$ (Fig. 6) shows that $\mathrm{BM}$ has the highest, while CG-HAZ has the weakest impact toughness. Without neglecting the lowest impact toughness found in CG-HAZ, the specimens from real welds, e.g. BM, WM and HAZ, have sufficient toughness as guarantied for BM in acc. to the standard for delivery condition, e.g. EN 10025-6, or KV $>27 \mathrm{~J}$ at $-40{ }^{\circ} \mathrm{C}$ [2]. Also, $K V_{i}=10$ to $45 \mathrm{~J}$ presents a minor part of the total absorbed energy, $K V$, and a slight 
decrease with a temperature decrease, while $K V_{p}$ values follows the general trend of $K V$. Typical results of EPFM parameters testing, and the corresponding resistance curves, are shown in Figs. 7 and 8.
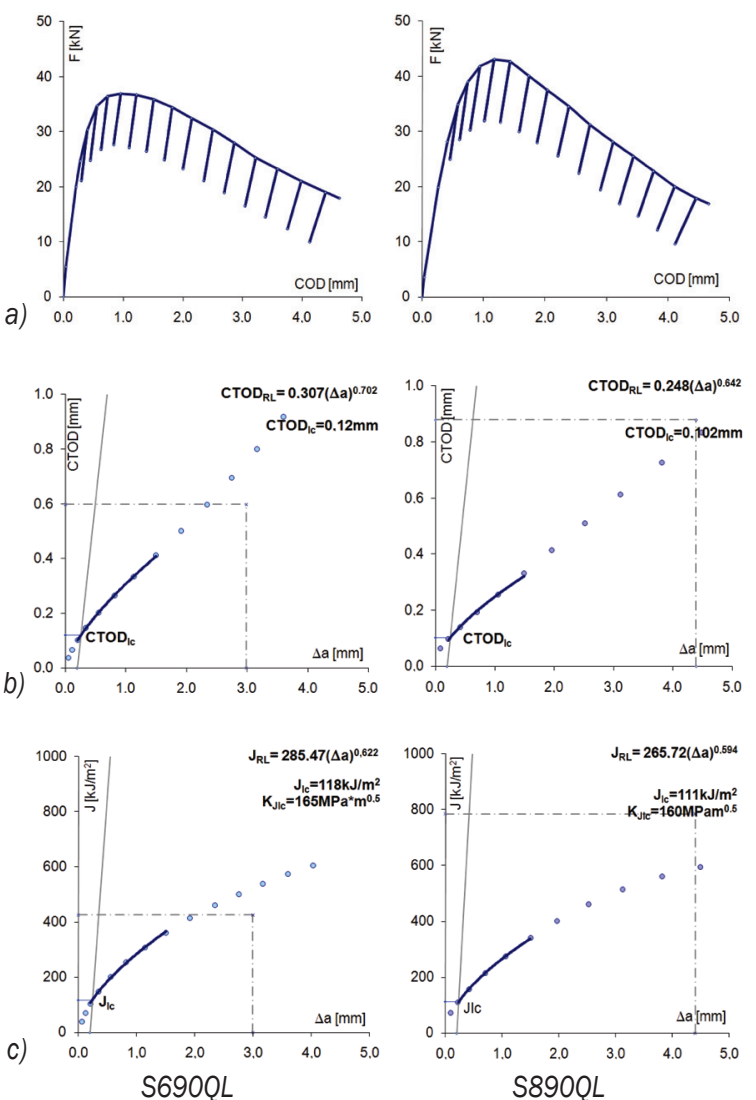

Fig. 8. Typical EPFM resistance curves for WM; a) F-COD, b) CTOD- $\Delta a, c) J-\Delta a$

Summarized range of critical materials EPFM and LEFM parameters testing are shown in Table 2.

Table 2. Critical material's EPFM and LEFM parameters

\begin{tabular}{cccc}
\hline Specimen & $J_{l C}\left[\mathrm{~kJ} / \mathrm{m}^{2}\right]$ & $C T O D_{l c}[\mathrm{~mm}]$ & $K_{J_{I C}}\left[\mathrm{MPa} \cdot \mathrm{m}^{0.5}\right]$ \\
\hline S690QL-BM & 201 to 238 & 0.25 to 0.27 & 202 to 227 \\
\hline S690QL-WM & 117 to 133 & 0.12 to 0.13 & 164 to 175 \\
\hline S890QL-BM & 173 to 188 & 0.14 to 0.15 & 200 to 204 \\
\hline S890QL-WM & 111 to 126 & 0.10 to 0.11 & 160 to 170 \\
\hline
\end{tabular}

\section{RELATIONSHIP TERMS}

If we consider experimentally obtained results of general toughness characteristics testing, both impact toughness, $K V$, and quasi-static toughness (critical fracture mechanics parameters), $J_{I c}, C T O D_{I c}, K_{J I c}$, it is possible to provide approximation terms. The same is possible for corresponding results of hardness and tensile testing. These approximation terms may be particularly helpful for a further assessment of costly fracture mechanics parameters testing. The terms definition is based on similar approaches founded in novel integrity assessment procedures, such as FITNET, as well in respective scientific research works [8] and [9].

The obtained Eqs. (1) to (3), also presented in Fig. 9. were used for the calculation (prediction) of critical fracture mechanics parameters for HAZ and CG-HAZ, where the corresponding impact toughness, $K V$, was experimentally determined.
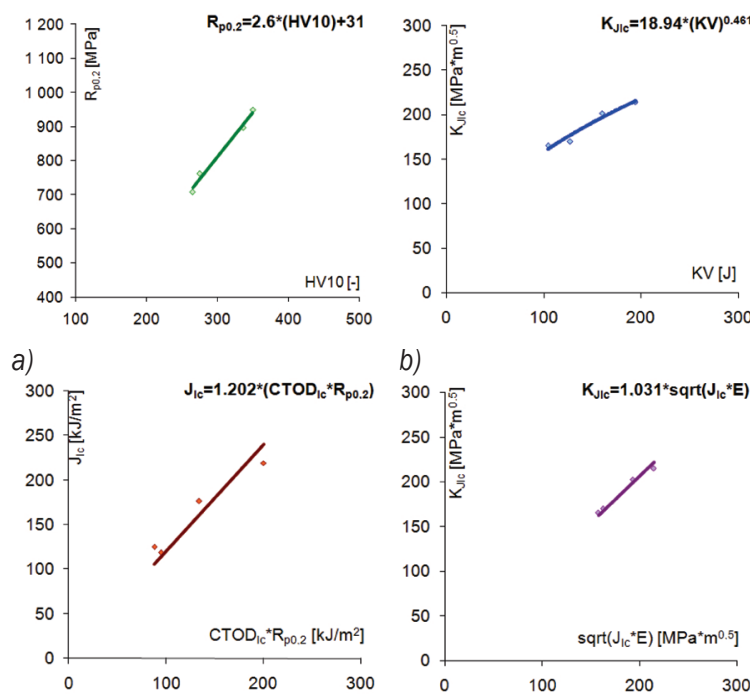

c)

d)

Fig. 9. Relationship terms between investigated mechanical properties of HSS welds; a) $\left.R p_{0.2}=f(H V), b\right) K_{J l c}=f(K V)$,

$$
\text { c) } \left.J_{l c}=f\left(C T O D_{l c}, R_{p 0,2}\right), d\right) K_{J l c}=f\left(J_{l c}, E\right)
$$

Finally, both experimentally obtained and by calculation approximated fracture resistance parameters are used to found the distribution of fracture resistance along welded joints, for both steels respectively, which is presented in Tables 3 to 6 .

The following are obtained relationship terms Fig. 9, where $E[\mathrm{GPa}]$ stand for Young's modulus:

$$
\begin{gathered}
K_{I c}=18.94 \cdot K V^{0.461}, \\
J_{I c}=1.202 \cdot\left(C T O D_{I c} \cdot R_{P_{0.2}}\right), \\
K_{I c}=1.031 \cdot \sqrt{J_{I c} \cdot E} .
\end{gathered}
$$




\section{CONCLUSION}

The summarized preview of average toughness distribution, and corresponding undermatching, UM, for investigated welded joints are shown in Tables 3 to 6 .

Table 3. Distribution of average impact toughness, KV [J], at room temperature $\left(20^{\circ} \mathrm{C}\right)$

\begin{tabular}{lcccc}
\hline Welded joint on & BM & HAZ & CG-HAZ & WM \\
\hline S690QL & 194 & 186 & 89 & 127 \\
\hline UMtoBM & - & 0.96 & 0.46 & 0.65 \\
\hline S890QL & 160 & 141 & 56 & 104 \\
\hline UMtoBM & - & 0.88 & 0.35 & 0.65 \\
\hline
\end{tabular}

Table 4. Distribution of average critical EPFM parameter, $J_{I C}$ $\left[\mathrm{kJ} / \mathrm{m}^{2}\right]$, at room temperature $\left(20^{\circ} \mathrm{C}\right)$

\begin{tabular}{lcccc}
\hline Welded joint on & BM & HAZ & CG-HAZ & WM \\
\hline S690QL & 222 & 201 & 90 & 122 \\
\hline UMtoBM & - & 0.91 & 0.41 & 0.55 \\
\hline S890QL & 176 & 148 & 54 & 119 \\
\hline UMtoBM & - & 0.85 & 0.31 & 0.68 \\
\hline
\end{tabular}

Table 5. Distribution of average critical EPFM parameter, $C T O D_{I c}$ $[\mathrm{mm}]$, at room temperature $\left(20^{\circ} \mathrm{C}\right)$

\begin{tabular}{lcccc}
\hline Welded joint on & BM & HAZ & CG-HAZ & WM \\
\hline S690QL & 0.26 & 0.26 & 0.12 & 0.13 \\
\hline UMtoBM & - & 1.00 & 0.46 & 0.50 \\
\hline S890QL & 0.22 & 0.19 & 0.07 & 0.12 \\
\hline UMtoBM & - & 0.86 & 0.32 & 0.55 \\
\hline
\end{tabular}

Table 6. Distribution of average critical LEFM parameter, $K_{I c}$ $\left[\mathrm{MPa} \cdot \mathrm{m}^{0.5}\right]$, at room temperature $\left(20^{\circ} \mathrm{C}\right)$

\begin{tabular}{lcccc}
\hline Welded joint on & BM & HAZ & CG-HAZ & WM \\
\hline S690QL & 227 & 205 & 137 & 168 \\
\hline UMtoBM & - & 0.90 & 0.60 & 0.74 \\
\hline S890QL & 202 & 177 & 107 & 166 \\
\hline UMtoBM & - & 0.88 & 0.53 & 0.82 \\
\hline
\end{tabular}

Eqs. (1) to (3) presented in Fig. 9 for the approximation of fracture mechanics parameters, $K_{J I c}$, $J_{I c}, C T O D_{I c}$, based on the known impact toughness, $\mathrm{KV}$, are valid only for welded joints executed with GMAW process, on high strength structural steels S690QL and S890QL respectively, in the thickness range of 20 to $30 \mathrm{~mm}$. However, future research may include effects of specimens thickness and testing temperatures to adjust more precisely provided approximation terms. Also, a similar approach may be applied to other type of materials and their welded joints.
From the point of applied welding technology, it should be noted that welded joints on the subject HSS, e.g. S690QL and S890QL, are obtained by the use of preheating, but without post-weld heat-treatment, PWHT. This was possible in one way, by producing the slightly strength undermatching joints ( $U M=0.89$ to 0.96 ). Also, this strength undermatching is followed with generally acceptable toughness undermatching (Tables 3 to 6) which should be particularly included in any design or structural assessment, for such kind of materials and joints.

Therefore, evaluated complete welded joints resistance (particularly represented in strength and toughness) should provide more than a satisfactory confidence, with minimum conservatism.

The complete toughness undermatching, $U M$, of welded joint characteristic zone's properties (in comparison to base metal, $\mathrm{BM}$ ) are found to be on the following lowest limits (from Tables 3 to 6):

- 0.85 , for real HAZ,

- $\quad 0.31$, for simulated CG-HAZ,

- 0.50 , for real WM.

Finally, the presented investigation and characterization approach, as well as the obtained results, could be helpful for a future setting of new acceptance criteria based on fracture mechanics parameters, or general toughness.

\section{ACKNOWLEDGMENT}

The presented paper has been made within project No 47029 financed by the Ministry of Science and Technology Development Republic of Serbia.

\section{REFERENCES}

[1] Kaiser, H.J., Kern, A., Niesen, T., Schriever, U. (2001). Modern high-strength steels with minimum yield strength up to $690 \mathrm{MPa}$ and high component safety, Proceedings of the 11th International Offshore and Polar Engineering Conference, Stavanger.

[2] EN 10025-6 (2004). Hot rolled products of structural steels, Part 6: Technical delivery conditions for flat products of high yield strength structural steels in the quenched and tempered condition. European Committee for Standardization, Brussels.

[3] High-strength heavy plates (2008). Weight savings combined with excellent weldability. VoestAlpine Grobblech, Linz.

[4] Hajro, I., Pasic, O., Burzic, Z. (2010). Characterization of welded joints on high-strength structural steels S690QL and S890QL. 2nd South-East European IIW International Congress, Sofia. 
[5] Gutierrez-Solana, C., Alvarez, L. (2001). FITNET - Basic Training Package. University of Cantabria, Cantabria.

[6] M-120 (2000). Material data sheets for structural steel, Norsok standard. Norwegian Technology Center, Oslo.

[7] M-101 (2000). Structural steel fabrication, Norsok standard. Norwegian Technology Center, Oslo.

[8] Fujita, H., Tanaka, M., Kamiya, O. (1982). Temperature dependence of JIc fracture toughness values in the structural steels and evaluation of the testing method. Transactions of the Iron and Steel Institute of Japan, vol. 22 , no. 2.

[9] ASTM E1820 (2001). Standard test method for measurement of fracture toughness. Annual Book of ASTM Standards, vol. 03.01.

[10] BS 7448-2 (1997). Fracture mechanics toughness tests - Part 2. Method for determination of KIc, critical CTOD and critical $J$ values of welds in metallic materials. British Standard Institute, London.

[11] Smoljan, B., Iljkić, D. (2010). Predictions of mechanical properties of quenched and tempered steel.
Strojniški vestnik - Journal of Mechanical Engineering, vol. 56, no. 2, p. 115-120.

[12] Liščić, B., Singer S., Smoljan, B. (2010). Prediction of quench-hardness within the whole volume of axiallysymmetric workpieces of any shape. Strojniški vestnik - Journal of Mechanical Engineering, vol. 56, no. 2, p. 104-114.

[13] EN 1011-2:2004. Welding - Recommendations for welding of metallic materials, Part 2, Arc welding of ferritic steels. European Committee for Standardization, Brussels.

[14] EN 12534:1999. Welding consumables - Wire electrodes, wires, rods and deposits for gas shielded metal arc welding of high strength steels - Classification. European Committee for Standardization, Brussels.

[15] EN 1043-1:1996. Destructive tests on welds in metallic materials. Hardness testing. Hardness test on arc welded joints. European Committee for Standardization, Brussels.

[16] EN 10045-1:1990. Charpy impact test on metallic materials. Test method ( $V$ - and U-notches). European Committee for Standardization, Brussels. 